\title{
Weight loss among women and men in the ASPIRE-VA behavioral weight loss intervention trial
}

Varsha Vimalananda, MD, $\mathrm{MPH}^{1,2}$;

Laura Damschroder, MS, MPH ${ }^{3}$;

Carol A. Janney, $\mathrm{PhD}^{3, *}$;

David Goodrich, EdD ${ }^{3}$;

H. Myra Kim, $\mathrm{ScD}^{4}$;

Robert Holleman, $\mathrm{MPH}^{3}$;

Leah Gillon, $\mathrm{MSW}^{3}$;

Lesley Lutes, $\mathrm{PhD}^{5, \dagger}$

${ }^{1}$ Center for Healthcare Organization and Implementation Research, Bedford VA Medical Center, Bedford MA USA;

${ }^{2}$ Boston University School of Medicine, Boston MA USA;

${ }^{3}$ VA Center for Clinical Management Research, VA Ann Arbor Healthcare System, Ann Arbor

MI USA;

${ }^{4}$ Center for Statistical Consultation and Research, University of Michigan, Ann Arbor MI USA;

${ }^{5}$ Department of Psychology, East Carolina University, Greenville NC USA

* present address: Department of Epidemiology and Biostatistics, Michigan State University

College of Human Medicine - Midland campus

${ }^{\dagger}$ present address: Department of Psychology, University of British Columbia - Okanagan

Campus, Kelowna, Canada

Keywords: sex, women, trial, weight loss, behavioral intervention, small changes

Running title: Sex-specific weight loss results in ASPIRE-VA

\section{Corresponding Author:}

Varsha Vimalananda, MD, MPH

Center for Healthcare Organization and Implementation Research (152)

Bedford VA Medical Center

200 Springs Road

Bedford MA 01730

Email: Varsha.vimalananda@va.gov

Word count: 3293

Tables: 5

Figures: 2

This is the author manuscript accepted for publication and has undergone full peer review but has not been through the copyediting, typesetting, pagination and proofreading process, which may lead to differences between this version and the Version record. Please cite this article as doi:10.1002/ oby.21574. 
Funding: Funded by VA HSR\&D/Diabetes QUERI, \#IBB 09-034; this funding source had no role in the conduct of the research and/or preparation of this manuscript. CAJ was supported by the VA Center for Clinical Management Research, Health Services Research and Development as a post-doctoral fellow at the VA Ann Arbor Healthcare System.

Disclosures: The authors have no conflicts of interest to disclose.

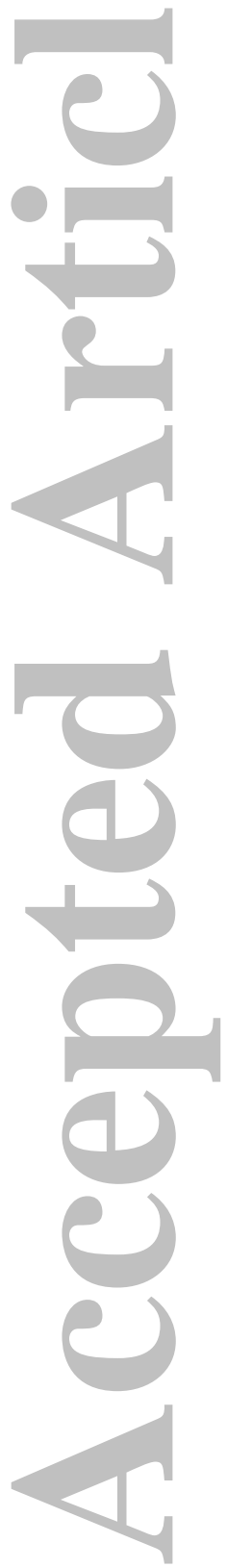




\section{STUDY IMPORTANCE:}

- Because barriers to weight loss differ by sex, women Veterans may experience different weight loss outcomes with behavioral programs than do men Veterans.

- At 12 months after baseline, women in both group-based weight loss programs (the small-changes ASPIRE-Group program and the usual-care MOVE! program) lost weight.

- At 12 months after baseline, men in all three programs lost weight; they lost more weight weight with the ASPIRE-Group compared to the MOVE! program.

- Mixed-sex, group-based programs can result in weight loss for both women and men

Veterans.
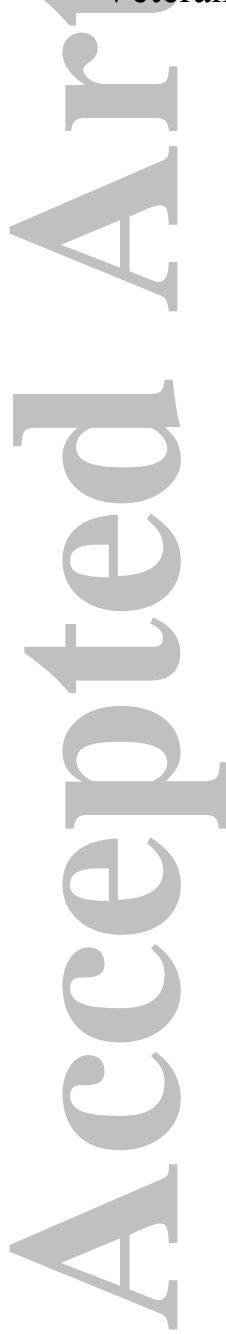


\section{Objective:}

To examine weight loss among women and men Veterans in a clinical trial comparing ASPIRE, a "small changes" weight-loss program using either mixed-sex group-visit or telephone-based coaching, to MOVE! ${ }^{\circledR}$, the usual mixed-sex group-based program.

\section{Methods:}

We used linear mixed-effects models to calculate adjusted percent weight change at 12 months by sex and compared outcomes across arms within sex.

\section{$\underline{\text { Results: }}$}

Analyses included 72 women (ASPIRE-Phone = 26; ASPIRE-Group = 26; MOVE! = 20) and 409 men (ASPIRE-Phone = 136; ASPIRE-Group = 134; MOVE! =139). At 12 months, women displayed significant weight loss from baseline in ASPIRE-Group (-2.6\%) and MOVE! (-2.7\%), but not ASPIRE-Phone ( $+0.2 \%)$. Between-arm differences in weight change among women were: ASPIRE-Group vs. ASPIRE-Phone, $-2.8 \%(\mathrm{p}=0.15)$; MOVE! vs. ASPIRE-Phone, $-2.8 \%$ $(p=0.20)$; and ASPIRE-Group vs. MOVE!, 0.0\% ( $p=1.0)$. At 12 months, men lost significant weight from baseline across arms (ASPIRE-Phone, -1.5\%; ASPIRE-Group, -2.5\%; MOVE!,$1.0 \%)$. Between-arm differences in weight change among men were: ASPIRE-Group vs. ASPIRE-Phone, $-0.9 \%(p=0.23)$; MOVE! vs. ASPIRE-Phone, $+0.5 \%(p=0.76)$; ASPIRE-Group Vs. MOVE!,$-1.5 \%(\mathrm{p}=0.03)$.

\section{Conclusions:}

Mixed-sex, group-based programs can result in weight loss for both women and men Veterans.

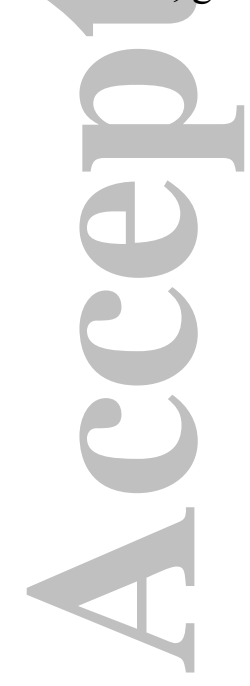




\section{Introduction}

Despite the rigors of active duty service in the U.S. Armed Forces, the prevalence of overweight and obesity has continued to steadily increase over the past two decades among active duty personnel. ${ }^{1,2}$ Upon retirement, military personnel are particularly susceptible to significant increases in weight. ${ }^{1,2}$ Among Veterans who receive health care from the Veterans Health Administration (VHA), for example, nearly $78 \%$ are overweight or obese and $41 \%$ are obese. ${ }^{3}$

To reduce the prevalence and long-term health consequences of overweight and obesity among Veterans, VHA developed MOVE! ${ }^{\circledR}$, a nationally-implemented weight management program. ${ }^{4,5}$ Overall, participation in MOVE! is associated with clinically significant weight loss, but the impact of the program may differ by sex. ${ }^{6}$ In a study of MOVE! in four Western states, women Veterans were more likely than men Veterans to participate in MOVE!, but less likely to attain clinically meaningful weight loss. ${ }^{6}$

It is a clinical imperative to better understand what types of weight loss programs might best serve women Veterans receiving health care from VHA. The number of women using VHA services has nearly doubled in the last decade ${ }^{7}$, and women are projected to increase from $6.5 \%$ currently to over $14 \%$ of the VHA population by $2033 .{ }^{8}$ Although the prevalence of obesity is similar among women and men Veterans $(21.2 \%$ and $22.2 \%$, respectively), the prevalence of severe obesity $\left(>=35.0 \mathrm{~kg} / \mathrm{m}^{2}\right)$ is higher among women Veterans compared to men Veterans (16.2\% and $11.1 \%$, respectively), representing a greater burden of disease among women. ${ }^{9}$ Furthermore, women Veterans have demonstrated interested in weight loss support through VHA. In a survey of women Veterans receiving behavioral health treatment in VHA, access to weight management programming was one of the top five health service priorities identified, and 
$62 \%$ of respondents indicated they were extremely likely to use this kind of service within the following six months. ${ }^{10}$

The literature suggests that barriers to weight loss among women and men differ, which may mean that different types of weight loss programs may be needed for women and men Veterans. For example, women Veterans are much more likely than men Veterans to have experienced military sexual trauma ${ }^{11}$, which may undermine their willingness to join a mixedsex, group-format weight loss program comprising mostly men. ${ }^{10}$ Anxiety is more common and regular exercise less common among women Veterans compared to men ${ }^{12}$, representing additional differences in barriers to weight loss.

Studies among the general population describe additional ways in which weight-loss barriers differ between women and men. Women have more significant childcare and eldercare responsibilities compared to men; such responsibilities may represent competing priorities with self-care, and limit the time and energy available for weight loss efforts. ${ }^{13}$ Additionally, women with obesity have an inaccurately low perception of cardiovascular disease risk ${ }^{13}$ and worse selfreported mental health than do men with obesity. ${ }^{14}$ These factors may reduce interest in engaging or succeeding in any type of weight management efforts.

We conducted a secondary analysis of data collected from the ASPIRE-VA trial to understand weight loss outcomes among women and men at 12 months based on assignment to one of three types of behavioral weight loss programs. ${ }^{15}$ ASPIRE-VA was a pragmatic, randomized, controlled study that evaluated whether a "small-changes" weight-loss approach, using either group-visit or individual telephone-based coaching, could help Veterans who were overweight or obese lose significantly more weight over a 12-month period compared to the usual MOVE! weight-loss program. ${ }^{15}$ We previously reported that participants in all three arms 
of the ASPIRE-VA trial lost significant weight at 12 months. Those in ASPIRE-Group lost significantly more weight than those in the other two treatment arms (-2.8 kg ASPIRE-Group vs. $-1.4 \mathrm{~kg}, \mathrm{p}=0.04$ for both ASPIRE-Phone and MOVE!). ${ }^{16}$

\section{Methods}

ASPIRE-VA compared three behavioral weight loss programs for Veterans, and has been described in detail elsewhere. ${ }^{15,16}$ Two of the programs were based on the ASPIRE (Aspiring for Lifelong Health) program, which used a small-changes approach that encouraged individuals to make small but cumulative changes in nutrition and physical activity. It was hypothesized that small changes could yield slower but more sustained weight loss compared to traditional behavioral treatments. Specifically, small changes were thought to reduce risk of weight gain over time by decreasing feelings of deprivation and satiation typically experienced with lowcalorie diets. $^{17,18}$

ASPIRE-VA was a pragmatic clinical trial ${ }^{19}$ which aimed to establish the effectiveness of the small-changes approach under "usual" conditions compared to the national referral process and weight loss program offered at all VHA facilities. This national program, MOVE!, was selected as the control arm for the study. Program specifications for MOVE! follow evidencebased clinical practice guidelines for obesity treatment disseminated by the VHA and the Department of Defense. ${ }^{20,21}$ However, sites vary considerably in guideline implementation with respect to the design and delivery of programming, which has been attributed to local contextual constraints and priorities. $^{21}$

Veterans were randomized to one of three interventions: ASPIRE delivered individually via telephone (ASPIRE-Phone), ASPIRE delivered via in-person mixed-sex groups (ASPIRE- 
Group), or the usual-care weight-loss program MOVE!, delivered via mixed-sex in-person groups. In both ASPIRE-Group and MOVE!, the majority of participants were men. Written informed consent was obtained from all participants. IRBs at both study sites approved all procedures.

STUDY SETTING AND POPULATION

ASPIRE-VA enrolled participants from two Midwestern VA medical centers. Eligible Veterans were men and women referred to the MOVE! program (body mass index $(\mathrm{BMI})>30 \mathrm{~kg} / \mathrm{m}^{2}$ or a BMI between $25-30 \mathrm{~kg} / \mathrm{m}^{2}$ with at least one obesity-related chronic health condition, without contraindications for weight loss). ${ }^{20}$ We excluded individuals already enrolled in a weight-loss study, receiving weight-loss treatment, or who were pregnant.

\section{INTERVENTION}

ASPIRE small-changes approach

The two ASPIRE programs (phone and group) used a small-changes approach. Rather than prescribing a pre-set goal such a daily calorie target ${ }^{22}$, the small-changes approach encouraged participants to set personalized goals for weight loss that were feasible within an individual's life context. $^{23-25}$ Goals were designed to achieve a modest daily caloric deficit (100-200 fewer calories) through increased physical activity and modifications to eating patterns that were attainable and self-reinforcing. ${ }^{26}$ Logbooks were provided to track food intake and pedometers were provided to track daily step count. Diet choices were guided by a modified Stoplight Food Guide, which categorized foods as "Green", "Yellow" and "Red" without having to count calories. ${ }^{27}$ The small changes are designed to be cumulative over time, yielding slower but 
longer-term weight loss that is more likely to be maintained given participants' enhanced sense of self-efficacy and mastery of self-regulatory lifestyle habits. Both ASPIRE-Phone and ASPIRE-Group sessions were led by a trained Lifestyle Coach.

Lifestyle Coaches were non-clinicians with strong interpersonal skills and at least a bachelor's degree, but no psychology, behavior change, or coaching experience. Coaches attended a three-day in-person training workshop, and received ongoing continuing education and supervision in one-on-one, group and peer formats. Every six months the Coaches had inperson booster training sessions.

ASPIRE was a manualized intervention in which the Coach sought to elicit active engagement and discussion with participants regarding key self-regulatory topics and skills based on social cognitive theory ${ }^{3}$, problem-solving therapy ${ }^{28}$, and motivational interviewing. ${ }^{29}$ Sessions encouraged participants to receive feedback and support on self-monitored progress toward personal goal attainment. Those in ASPIRE-Group typically met in small groups with 5-8 participants and the Lifestyle Coach at prescheduled times at the medical center. These groups were closed to new participants after the program began. ASPIRE-Phone participants had individual phone calls with the Lifestyle Coach arranged at mutually convenient times.

ASPIRE-Group sessions were weekly for 90 minutes in the active treatment phase of the first 3 months. The maintenance phase in months 4-12 comprised bi-weekly 60-minute sessions for 6 months, and then monthly 60 -minute sessions for the next 3 months. The total treatment dose was 33 hours. ASPIRE-Phone sessions were up to 30 minutes in the first 3 months and 20 minutes in the maintenance phase, for a total treatment dose of 11 hours. The small-changes intervention approach remained consistent over time. 
MOVE! weight management program (control arm)

As noted, though national guidelines for MOVE! exist, local contextual features often determine specifics of the design and delivery of the program at individual sites. ${ }^{21}$ About threequarters of MOVE sessions in VHA are delivered in group formats ${ }^{21}$, and MOVE! at our study sites were delivered predominantly via groups. Groups were open; new participants could join any time, though they were not included in our study sample. MOVE! provided individualized handouts on health behavior change topics, counseling and behavior modification support. ${ }^{20,21}$ Psychoeducation topics in MOVE! were discussed didactically. Sessions were led by an interdisciplinary group of providers, including dietitians, health psychologists, and physical therapists who rotated from session to session. A pedometer and an optional self-monitoring log were provided.

MOVE! participants were offered 90-minute 11-12 weekly sessions in the active treatment phase, during months 1-3. In the maintenance phase in months 4-12, both sites offered drop-in follow-up groups. Maintenance sessions in months 4-12 were 90 minutes every 3 months at one site, and 60 minutes every two weeks at the other site. Overall, Veterans in MOVE! were offered a total treatment dose of 22-35 hours. The intervention approach remained consistent over time.

\section{DATA COLLECTION}

Demographic and clinical data were collected at baseline. Medical diagnoses from medical records were used to compute the Charlson severity index. ${ }^{30}$ At baseline, 3 months, and 12 months, we recorded anthropometric measures (height, weight, and waist circumference) and self-reported measures including a Food Frequency Questionnaire ${ }^{31}$, and downloaded pedometer 
data. Satisfaction with the Lifestyle Coach/MOVE! leader was elicited via survey at 12 months. Questions included whether participants had confidence and trust in their Coach/leader (Yes, always; Yes, sometimes; No), the degree of Coach/leader courtesy (Excellent; Very Good; Good; Fair; Poor), whether participants were treated with respect (Yes, always; Yes, sometimes; No); and whether Coach/leader answers to the participant's questions were understandable (Yes, always; Yes, sometimes; No).

\section{DATA ANALYSIS}

Main Analysis: The primary outcome was percent weight change at 12 months. We used linear mixed-effects models to model weight at baseline, 3, and 12 months, using an intent-to-treat cohort of all enrolled participants $(\mathrm{N}=481)$. The models included each subject as a random intercept to adjust for within-patient correlation of the repeated measures and fixed predictors of sex, study arm indicators, 3- and 12-month time indicators, three way interactions of time by study arm by sex, and all lower two-way interactions. The summary measures were expressed as mean percent weight change (and its 95\% confidence interval) at both 3 and 12 months for each sex by intervention group, estimated using predicted weights based on the model. Weights were compared across arms within sex at 3 and 12 months using appropriate interaction terms based on the model. Bonferroni correction was used to account for the three pairwise comparisons across study arms within each sex.

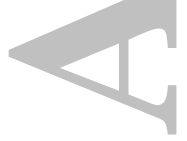

Analyses of Secondary Outcomes: We explored additional potential reasons for differences seen across arms in percent of weight lost among women and men. First, we calculated engagement as measured by the number of sessions completed by sex in each study arm, using ANOVA to 
evaluate for differences across arms. Second, we examined differences in satisfaction with the Coach/MOVE! leader across the three programs using chi-square tests to generate a $\mathrm{p}$-value for each question, by sex. Additional outcomes included diet and exercise measures, for which we calculated changes from baseline at 3 and 12 months for each arm by sex.

\section{Results}

481 Veterans were recruited and enrolled. There were 72 women (ASPIRE-Phone $=26$; ASPIRE-Group = 26; MOVE! = 20) and 409 men $($ ASPIRE-Phone = 136; ASPIRE-Group $=$ 134 ; MOVE! $=139$ ) in the study sample (Table 1). Overall, women represented $15 \%$ of the sample. Compared to men, women were younger (46.5 vs. 56.5 years), more highly educated, had fewer comorbidities, and were more commonly depressed at baseline. Mean baseline weight was $99.3 \mathrm{~kg}$ among women and $115.4 \mathrm{~kg}$ among men. Of the 481 who were enrolled, 72 (15\%) did not have any follow-up assessments at all over the study period. The remaining 409 participants $(85 \%)$ had at either one or both follow-up assessments at 3 or 12 months.

\section{Percent weight change}

Table 2 shows the percent and absolute weight change in each study arm at 3 months and 12 months by sex based on the weight model. In Table 2 , if the percent weight loss is negative and its $95 \%$ confidence interval does not include zero, it indicates significant weight loss from baseline. Figures 1 and 2 show the percent weight changes from baseline for women and for men, respectively.

At 3 months, women did not lose significant weight from baseline in any arm. At 12 months, women lost significant weight from baseline in ASPIRE-Group $[-2.6 \%(-4.8 \%,-0.5 \%)]$ 
and MOVE! $[-2.7 \%(-5.2 \%,-0.1 \%)]$, but not in ASPIRE-Phone $[+0.2 \%(-2.1 \%,+2.5 \%)]$. The weight at 12 months did not vary across arms among women $(p=0.14)$; though across-group difference was not significant, pairwise comparisons between groups are reported (Table 3). Men lost statistically significant weight from baseline in all three study arms at both 3 months and 12 months. Weight loss at 12 months in the three arms was: ASPIRE-Phone [-1.5\% $(-2.4 \%,-0.7 \%)]$; ASPIRE-Group [-2.5\% (-3.3\%, -1.7\%)]; MOVE! [-1.0\% (-1.8\%, -0.2\%)]. Percent weight loss differed across arms $(\mathrm{p}=0.04)$. In pairwise comparisons, the difference in weight change between ASPIRE-Group vs. MOVE! was significant $(-1.5 \%, \mathrm{p}=0.03)$.

Secondary outcomes

Both women and men completed more sessions in the two ASPIRE programs than they did in MOVE! (Table 4). Differences across arms in sessions completed were significant among men $(\mathrm{p}<0.001)$ but not among women $(\mathrm{p}=0.21)$.

With respect to satisfaction measures (Table 5), women reported especially high confidence and trust in the Coach/leader and receiving understandable answers to important health questions for the ASPIRE programs compared to MOVE!. Diet and exercise measures were similar across the three programs among women and men (Table S1).

\section{Discussion}

Our findings, which examine weight loss outcomes separately among women and men, provide an important complement to the findings reported for the ASPIRE-VA study population as a whole. Those analyses included both women and men but did not examine weight loss outcomes by sex. In those analyses, Veterans lost weight in both ASPIRE programs, but not 
MOVE!, at 3 months. ${ }^{16}$ At 12 months, Veterans lost weight from baseline in all three arms, with significantly greater weight loss in the ASPIRE-Group arm than in ASPIRE-Phone or MOVE!. In this study, we found that weight loss outcomes for men were similar to those in the overall analysis, except that at 3 months men lost weight in all three arms, and at 12 months, ASPIREGroup was superior only to MOVE!.

The pattern of weight loss we observed among women contrasts with that reported among the ASPIRE-VA study population as a whole, and among men in our study. Women did not lose significant weight in any arm at 3 months. At 12 months, there was significant weight loss from baseline in both ASPIRE-Group and MOVE!, but not ASPIRE-Phone. There were not statistically significant differences across study arms, possibly due to the small number of women participants.

Better weight loss results for men with ASPIRE-Group as compared to MOVE! may be related to its small-changes approach. ASPIRE was initially designed predominantly for people who might be averse to traditional behavioral therapies emphasizing moderate to severe calorie restriction and "off-limit" foods. ASPIRE uses a "shaping" approach that is positive in its orientation to substitute obviously unhealthy behaviors with healthier choices that are acceptable and feasible within a Veteran's lifestyle relative to their current patterns. The coaching style of ASPIRE, which aimed to improve participants' sense of self-efficacy, may have been more effective than the more didactic psychoeducational approach used by MOVE! at the two study sites during the time of the ASPIRE-VA trial.

However, ASPIRE-Group and MOVE! differed in other ways that may explain the findings in men, including ASPIRE's smaller, closed group, expectation of self-monitoring, consistency of group leaders, and non-clinical group leaders. ASPIRE-Group may have provided 
a more intensive and consistent experience, which facilitated better group cohesion and coachparticipant relationship satisfaction, leading in turn to better engagement as measured by sessions completed, and subsequently greater weight loss. ${ }^{16,32}$ While ASPIRE-Phone utilized the smallchanges approach, its individual, phone-based delivery mode, by design, did not have the potential benefits accruing from having strong group cohesion. It needs to be noted that MOVE! program guidance has been updated since the ASPIRE-VA trial and now encourages a more interactive coaching approach, closed groups, and use of a consistent coach (see www.move.va.gov).

We observed poor short-term (3-month) weight loss among women in each study arm. Recent studies of data from other behavioral weight-loss trials ${ }^{33-35}$ suggest that outcomes in the first few months predict clinically significant long-term weight loss. Clinically meaningful weight loss is important to reduce downstream problems from obesity-related morbidity and impairment. Women did lose weight in both group-based programs by 12 months, though, as among men, the modest percent of weight lost has limited clinical significance. Early weight loss may represent a promising target for future efforts to effectively treat obesity among women Veterans.

It is striking that women in the ASPIRE-Phone arm did not lose weight from baseline at either assessment point, despite similarly high levels of engagement and satisfaction in both ASPIRE arms. Given certain barriers to weight loss that are more common among women, such as caretaking responsibilities and military sexual trauma histories, we anticipated that women in ASPIRE-VA would engage better, be more satisfied, and lose more weight with individual phone calls as compared to prescheduled and mixed-sex (predominantly male) groups. However, 
our findings, while not definitive, do not suggest any weight-loss benefit among women in a oneon-one phone-based program.

In prior VHA research, women have reported a preference for sex-specific services for PTSD, depression, and coping with chronic medical conditions. ${ }^{10,36,37}$ Our results suggest that sex-specific services for weight loss may not necessarily be a better approach than mixed-sex groups for women Veterans; our mixed-sex, group-based programs resulted in weight loss for both women and men Veterans. This outcome may be driven in part by the way the respective Coaches interacted with group participants e.g., by creating a safe environment for both sexes. Further research is needed to understand what attributes of Coaches or their interaction with groups contributes to equally positive weight outcomes. It may be that resources which would otherwise be spent on developing sex-specific weight loss services for women could be channeled instead into other sex-specific services with evidence of strong patient preference and/or demonstrably better clinical outcomes.

\section{Limitations}

This study is not without limitations. There were small numbers of women in each program and thus, the lack of significant differences for women must be interpreted with caution. While the low proportion of women in the ASPIRE-VA trial is slightly higher than the general population served by the VHA, our power to detect significant differences was limited. However, even with our small sample of women, we identified a trend towards better weight loss in both group-based programs, which is a plausible finding warranting further investigation in future studies. There was little variability in satisfaction with the Lifestyle Coach/MOVE! leader between ASPIRE study arms, which may be one explanation for similarities in weight loss 
across these programs. Weight loss is believed to be mediated by improvements in diet and physical activity, but we did not find significant changes nor differences in these behaviors between sexes in these measures. It is possible that we lacked the power to detect differences in diet and exercise measures across study arms. Even though research grade pedometers, as used in the study, have been shown to be reliable and valid ${ }^{38-40}$, participants may not have worn the pedometers consistently, which may have contributed to null findings. It is also possible that the magnitude of differences between groups is at the level of the composite changes in diet and exercise, as reflected in weight.

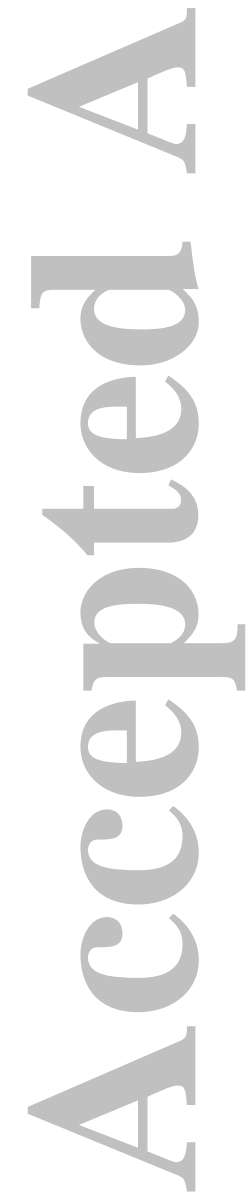




\section{REFERENCES}

1. Armed Forces Health Surveillance Center. Incidence and prevalence of select cardiovascular risk factors and conditions, active component, U.S. Armed Forces, 2003-2012. MSMR, 2013. 20(12), 16-19.

2. Reyes-Guzman CM, Bray RM, Forman-Hoffman VL, Williams J. Overweight and obesity trends among active duty military personnel: a 13-year perspective. Am J Prev Med 2015;48:145-53.

3. Department of Veterans Affairs DoD. VA/DoD Clinical Practice Guideline for Screening and Management of Overweight and Obesity. In: Department of Veterans Affairs DoD, ed. Washington, D.C.: Office of Quality and Performance publication 10Q-CPG/Obesity-06; 2014.

4. Maguen $S$, Madden $E$, Cohen B, et al. The relationship between body mass index and mental health among Iraq and Afghanistan veterans. J Gen Intern Med 2013;28 Suppl 2:S563-70.

5. Rosenberger PH, Ning Y, Brandt C, Allore H, Haskell S. BMI trajectory groups in veterans of the Iraq and Afghanistan wars. Prev Med 2011;53:149-54.

6. Littman AJ, Boyko EJ, McDonell MB, Fihn SD. Evaluation of a weight management program for veterans. Prev Chronic Dis 2012;9:E99.

7. Frayne SM, Phibbs CS, Saechao F, al. e. Demographics, utilization, costs of care, and health profile. Washington, D.C.; 2014.

8. Yano EM, Hayes $P$, Wright $S$, et al. Integration of women veterans into VA quality improvement research efforts: what researchers need to know. J Gen Intern Med 2010;25 Suppl 1:56-61.

9. Das SR, Kinsinger LS, Yancy WS, Jr., et al. Obesity prevalence among veterans at Veterans Affairs medical facilities. Am J Prev Med 2005;28:291-4.

10. Kimerling R, Bastian LA, Bean-Mayberry BA, et al. Patient-centered mental health care for female veterans. Psychiatr Serv 2015;66:155-62.

11. Kimerling $R$, Street $A E$, Pavao J, et al. Military-related sexual trauma among Veterans Health Administration patients returning from Afghanistan and Iraq. Am J Public Health 2010;100:1409-12. 12. Grossbard JR, Lehavot K, Hoerster KD, Jakupcak M, Seal KH, Simpson TL. Relationships among veteran status, gender, and key health indicators in a national young adult sample. Psychiatr Serv 2013;64:547-53.

13. Mosca L, Hammond G, Mochari-Greenberger H, Towfighi A, Albert MA. Fifteen-Year Trends in Awareness of Heart Disease in Women: Results of a 2012 American Heart Association National Survey. Circulation 2013.

14. Kolotkin RL, Crosby RD, Williams GR. Health-related quality of life varies among obese subgroups. Obes Res 2002;10:748-56.

15. Lutes LD, Dinatale E, Goodrich DE, et al. A randomized trial of a small changes approach for weight loss in veterans: design, rationale, and baseline characteristics of the ASPIRE-VA trial. Contemp Clin Trials 2013;34:161-72.

16. Damschroder LJ, Lutes LD, Kirsh S, et al. Small-changes obesity treatment among veterans: 12month outcomes. Am J Prev Med 2014;47:541-53.

17. Hill JO, Wyatt HR, Peters JC. Energy balance and obesity. Circulation 2012;126:126-32.

18. Brown WJ, Williams L, Ford JH, Ball K, Dobson AJ. Identifying the energy gap: magnitude and determinants of 5-year weight gain in midage women. Obes Res 2005;13:1431-41.

19. Thorpe KE, Zwarenstein M, Oxman AD, et al. A pragmatic-explanatory continuum indicator summary (PRECIS): a tool to help trial designers. Cmaj 2009;180:E47-57.

20. Kinsinger LS, Jones KR, Kahwati L, et al. Design and dissemination of the MOVE! WeightManagement Program for Veterans. Prev Chronic Dis 2009;6:A98.

21. Kahwati LC, Lewis MA, Kane H, et al. Best practices in the Veterans Health Administration's MOVE! Weight management program. Am J Prev Med 2011;41:457-64. 
22. Wing RR. Behavioral Treatment of Obesity. In: Wadden TA, Stunkard AJ, eds. Handbook of Obesity Treatment. New York, NY: Guilford Press; 2002:357-79.

23. Lutes LD, Winett RA, Barger SD, et al. Small changes in nutrition and physical activity promote weight loss and maintenance: 3-month evidence from the ASPIRE randomized trial. Ann Behav Med 2008;35:351-7.

24. Damschroder LJ, Lutes LD, Goodrich DE, Gillon L, Lowery JC. A small-change approach delivered via telephone promotes weight loss in veterans: results from the ASPIRE-VA pilot study. Patient Educ Couns 2010;79:262-6.

25. Lutes LD, Daiss SR, Barger SD, Read M, Steinbaugh E, Winett RA. Small changes approach promotes initial and continued weight loss with a phone-based follow-up: nine-month outcomes from ASPIRES II. Am J Health Promot 2012;26:235-8.

26. Luna B, Feinglos MN. Drug-induced hyperglycemia. Jama 2001;286:1945-8.

27. Epstein LH, Paluch RA, Beecher MD, Roemmich JN. Increasing healthy eating vs. reducing high energy-dense foods to treat pediatric obesity. Obesity (Silver Spring) 2008;16:318-26.

28. Salpeter SR, Buckley NS, Kahn JA, Salpeter EE. Meta-analysis: metformin treatment in persons at risk for diabetes mellitus. Am J Med 2008;121:149-57 e2.

29. Rollnick S, Miller WR, Butler CC. Motivational Interviewing in Health Care: Helping Patients Change Behavior. New York: The Guilford Press; 2008.

30. Charlson ME, Pompei P, Ales KL, MacKenzie CR. A new method of classifying prognostic comorbidity in longitudinal studies: development and validation. J Chronic Dis 1987;40:373-83.

31. Thompson FE, Midthune D, Subar AF, Kahle LL, Schatzkin A, Kipnis V. Performance of a short tool to assess dietary intakes of fruits and vegetables, percentage energy from fat and fibre. Public Health Nutr 2004;7:1097-105.

32. Golay A, Brock E, Gabriel R, et al. Taking small steps towards targets - perspectives for clinical practice in diabetes, cardiometabolic disorders and beyond. Int J Clin Pract 2013;67:322-32.

33. Miller CK, Nagaraja HN, Weinhold KR. Early weight-loss success identifies nonresponders after a lifestyle intervention in a worksite diabetes prevention trial. J Acad Nutr Diet 2015;115:1464-71.

34. Unick JL, Hogan PE, Neiberg RH, et al. Evaluation of early weight loss thresholds for identifying nonresponders to an intensive lifestyle intervention. Obesity (Silver Spring) 2014;22:1608-16.

35. Unick JL, Neiberg RH, Hogan PE, et al. Weight change in the first 2 months of a lifestyle intervention predicts weight changes 8 years later. Obesity (Silver Spring) 2015;23:1353-6.

36. Bastian LA, Trentalange M, Murphy TE, et al. Association between Women Veterans' Experiences with VA Outpatient Health Care and Designation as a Women's Health Provider in Primary Care Clinics. Women's Health Issues;24:605-12.

37. Washington DL, Bean-Mayberry B, Mitchell MN, Riopelle D, Yano EM. Tailoring VA Primary Care to Women Veterans: Association with Patient-Rated Quality and Satisfaction. Women's Health Issues;21:S112-S9.

38. Wallmann-Sperlich B, Froboese I, Reed JL, Mathes S, Sperlich B. How accurate are Omron X-HJ304-E and Yamax SW-700/701 pedometers at different speeds and various inclinations? J Sports Med Phys Fitness 2015;55:113-7.

39. Holbrook EA, Barreira TV, Kang M. Validity and reliability of Omron pedometers for prescribed and self-paced walking. Med Sci Sports Exerc 2009;41:670-4.

40. Bravata DM, Smith-Spangler C, Sundaram V, et al. Using pedometers to increase physical activity and improve health: a systematic review. Jama 2007;298:2296-304. 
Table 1 - Demographic and clinical characteristics at baseline in the ASPIRE-VA study

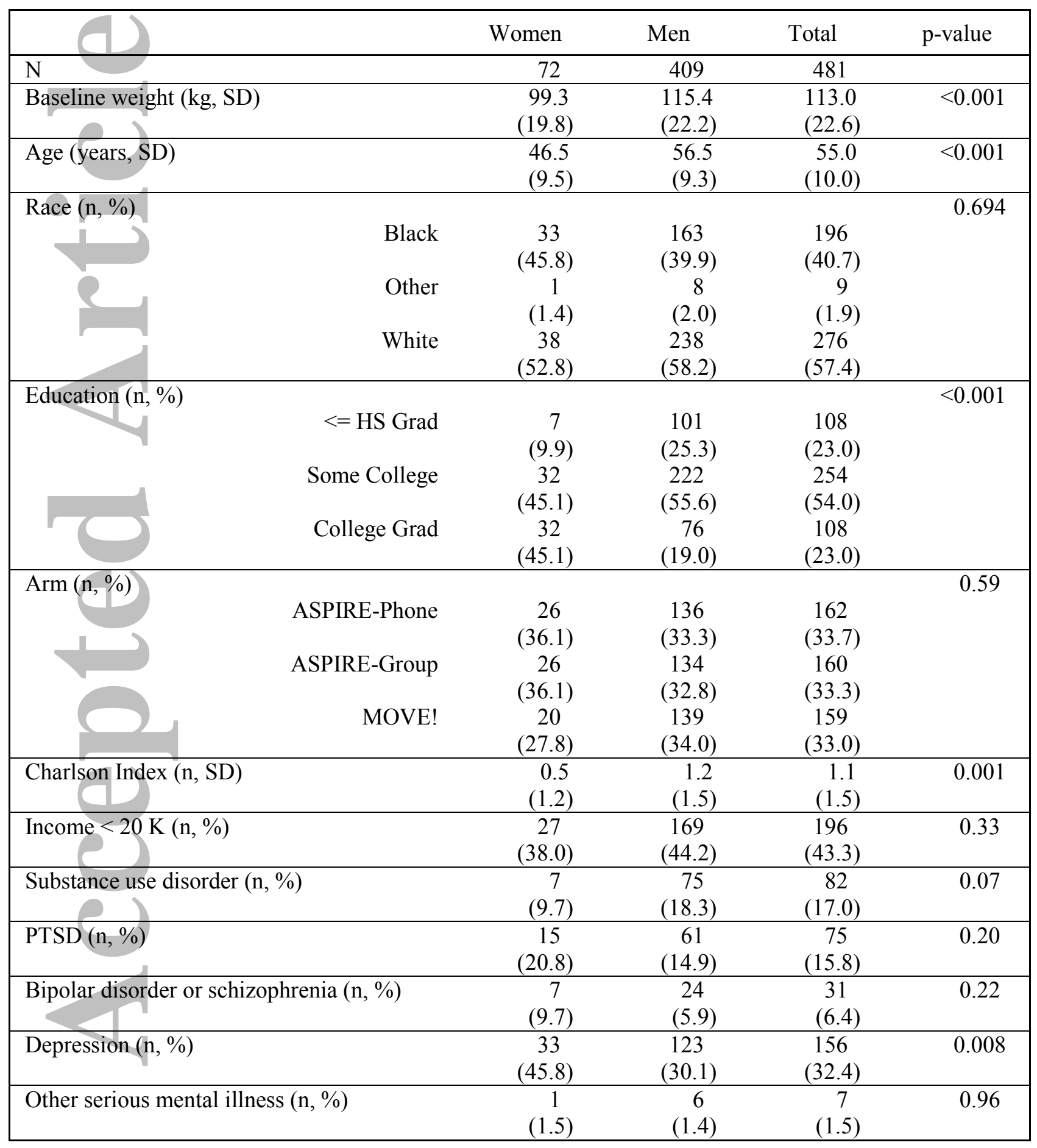


Table 2 - Model-based* percent and absolute weight change $\dagger$ among women and men in each study arm at 3 and 12 months in the ASPIRE-VA study

\begin{tabular}{|c|c|c|c|c|}
\hline & \multicolumn{3}{|c|}{ Study Arm } & \multirow[b]{2}{*}{ p-value } \\
\hline & ASPIRE-Phone & ASPIRE-Group & MOVE! & \\
\hline Women & $\mathrm{N}=26$ & $\mathrm{~N}=26$ & $\mathrm{~N}=20$ & \\
\hline $\begin{array}{l}\text { Baseline } \\
\text { weight }(\mathrm{kg})\end{array}$ & $\begin{array}{c}96.1 \\
(17.0)\end{array}$ & $\begin{array}{l}102.6 \\
(24.2)\end{array}$ & $\begin{array}{c}99.0 \\
(16.7)\end{array}$ & 0.50 \\
\hline \multicolumn{5}{|c|}{3 months weight change from baseline } \\
\hline$(\%)$ & $\begin{array}{c}0.1 \\
(-2.2,2.3) \\
\end{array}$ & $\begin{array}{c}-0.6 \\
(-2.8,1.6) \\
\end{array}$ & $\begin{array}{c}-1.0 \\
(-3.7,1.7)\end{array}$ & 0.83 \\
\hline $\mathrm{kg}$ & $\begin{array}{c}0.0 \\
(-2.1,2.2)\end{array}$ & $\begin{array}{c}-0.6 \\
(-2.8,1.6)\end{array}$ & $\begin{array}{c}-1.0 \\
(-3.7,1.7)\end{array}$ & 0.82 \\
\hline \multicolumn{5}{|c|}{12 months weight change from baseline } \\
\hline$(\%)$ & $\begin{array}{c}0.2 \\
(-2.1,2.5)\end{array}$ & $\begin{array}{c}-2.6 \\
(-4.8,-0.5)\end{array}$ & $\begin{array}{c}-2.7 \\
(-5.2,-0.1)\end{array}$ & 0.14 \\
\hline $\mathrm{kg}$ & $\begin{array}{c}0.2 \\
(-2.0,2.4)\end{array}$ & $\begin{array}{c}-2.7 \\
(-5.0,-0.5)\end{array}$ & $\begin{array}{c}-2.6 \\
(-5.2,-0.1)\end{array}$ & 0.12 \\
\hline Men & $\mathrm{N}=136$ & $\mathrm{~N}=134$ & $\mathrm{~N}=139$ & \\
\hline $\begin{array}{l}\text { Baseline } \\
\text { weight }(\mathrm{kg})\end{array}$ & $\begin{array}{l}115.7 \\
(22.2)\end{array}$ & $\begin{array}{l}114.3 \\
(20.8)\end{array}$ & $\begin{array}{l}116.2 \\
(23.7)\end{array}$ & 0.76 \\
\hline \multicolumn{5}{|c|}{3 months weight change from baseline } \\
\hline$(\%)$ & $\begin{array}{c}-1.5 \\
(-2.3,-0.7)\end{array}$ & $\begin{array}{c}-2.1 \\
(-3.0,-1.3)\end{array}$ & $\begin{array}{c}-0.9 \\
(-1.7,-0.1)\end{array}$ & 0.10 \\
\hline $\mathrm{kg}$ & $\begin{array}{c}-1.7 \\
(-2.6,-0.8)\end{array}$ & $\begin{array}{c}-2.4 \\
(-3.4,-1.5)\end{array}$ & $\begin{array}{c}-1.0 \\
(-2.0,-0.1)\end{array}$ & 0.12 \\
\hline \multicolumn{5}{|c|}{12 months weight change from baseline } \\
\hline$(\%)$ & $\begin{array}{c}-1.5 \\
(-2.4,-0.7)\end{array}$ & $\begin{array}{c}-2.5 \\
(-3.3,-1.7)\end{array}$ & $\begin{array}{c}-1.0 \\
(-1.8,-0.2)\end{array}$ & 0.044 \\
\hline $\mathrm{kg}$ & $\begin{array}{c}-1.8 \\
(-2.8,-0.8)\end{array}$ & $\begin{array}{c}-2.8 \\
(-3.8,-1.8)\end{array}$ & $\begin{array}{c}-1.2 \\
(-2.1,-0.2)\end{array}$ & 0.053 \\
\hline
\end{tabular}

* Estimated based on the linear mixed-effects model of weight at all assessment times $\dagger$ mean $(95 \%$ confidence interval) 
Table 3 - Pairwise comparisons of weight loss from baseline at 12 months by study arm, based on linear mixed-effects models in the ASPIRE-VA study*

\begin{tabular}{|l|c|c|}
\hline & $\begin{array}{c}\text { Mean difference in } \\
\text { percent weight loss } \\
(95 \% \mathrm{CI})\end{array}$ & $\begin{array}{c}\text { p-value } \\
\text { with Bonferroni correction }\end{array}$ \\
\hline Women & & 0.15 \\
\hline ASPIRE-Group vs. ASPIRE-Phone & $-2.8(-6.0,0.3)$ & 0.20 \\
\hline MOVE! vs. ASPIRE-Phone & $-2.8(-6.3,0.6)$ & 1.00 \\
\hline ASPIRE-Group vs. MOVE! & $0.0(-3.4,3.4)$ & 0.23 \\
\hline Men & & 0.76 \\
\hline ASPIRE-Group vs. ASPIRE-Phone & $-0.9(-2.1,0.2)$ & 0.03 \\
\hline MOVE! vs. ASPIRE-Phone & $0.5(-0.6,1.7)$ & \\
\hline ASPIRE-Group vs. MOVE! & $-1.5(-2.6,-0.3)$ & \\
\hline
\end{tabular}

* Estimated based on the linear mixed-effects model of weight at all assessment times
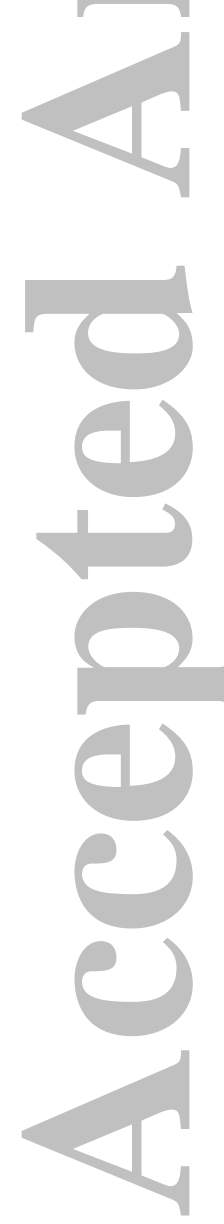
Table 4 - Intensive and maintenance sessions for weight loss completed for women and men Veterans by study arm* in the ASPIRE-VA study

\begin{tabular}{|c|c|c|c|c|c|c|c|c|c|}
\hline & \multicolumn{3}{|c|}{$\begin{array}{c}\text { ASPIRE-Phone } \\
\text { Women }=26 \\
\text { Men }=114\end{array}$} & \multicolumn{3}{|c|}{$\begin{array}{c}\text { ASPIRE-Group } \\
\text { Women }=26 \\
\text { Men }=115\end{array}$} & \multicolumn{3}{|c|}{$\begin{array}{c}\text { MOVE! } \\
\text { Women=20 } \\
\text { Men }=119\end{array}$} \\
\hline Sessions & $\begin{array}{l}\text { Inten- } \\
\text { sive: } \\
1-3 \text { mos }\end{array}$ & $\begin{array}{c}\text { Main- } \\
\text { tenance: } \\
\text { 4-12 mos }\end{array}$ & Total & $\begin{array}{l}\text { Inten- } \\
\text { sive: } \\
1-3 \text { mos }\end{array}$ & $\begin{array}{c}\text { Main- } \\
\text { tenance: } \\
\text { 4-12 mos }\end{array}$ & Total & $\begin{array}{l}\text { Inten- } \\
\text { sive: } \\
1-3 \text { mos }\end{array}$ & $\begin{array}{l}\text { Main- } \\
\text { tenance: } \\
4-12 \text { mos }\end{array}$ & Total \\
\hline $\begin{array}{l}\text { Planned } \\
\text { number of } \\
\text { sessions }\end{array}$ & 12 & 16 & 28 & 12 & 16 & 28 & 6 & 18 & 24 \\
\hline Women** & $\begin{array}{c}6.8 \\
(3.9)\end{array}$ & $\begin{array}{c}4.6 \\
(4.7)\end{array}$ & $\begin{array}{l}11.4 \\
(7.9)\end{array}$ & $\begin{array}{c}5.9 \\
(4.8)\end{array}$ & $3.8(5.1)$ & $\begin{array}{c}9.8 \\
(9.4)\end{array}$ & $\begin{array}{c}3.3 \\
(3.1)\end{array}$ & $3.2(5.0)$ & $\begin{array}{c}6.4 \\
(6.4)\end{array}$ \\
\hline Mentll & $\begin{array}{c}8.0 \\
(3.8)\end{array}$ & $\begin{array}{c}7.9 \\
(6.6)\end{array}$ & $\begin{array}{l}15.9 \\
(9.7)\end{array}$ & $\begin{array}{c}7.0 \\
(4.3)\end{array}$ & $6.5(6.1)$ & $\begin{array}{l}13.5 \\
(9.7)\end{array}$ & $\begin{array}{c}3.2 \\
(3.3)\end{array}$ & $2.2(3.8)$ & $\begin{array}{c}5.4 \\
(5.9)\end{array}$ \\
\hline
\end{tabular}

*mean, SD

$* * \mathrm{p}$-value for total sessions completed across all arms $=0.21$

$\dagger \mathrm{p}$-value for total sessions completed across all arms $=<0.001$

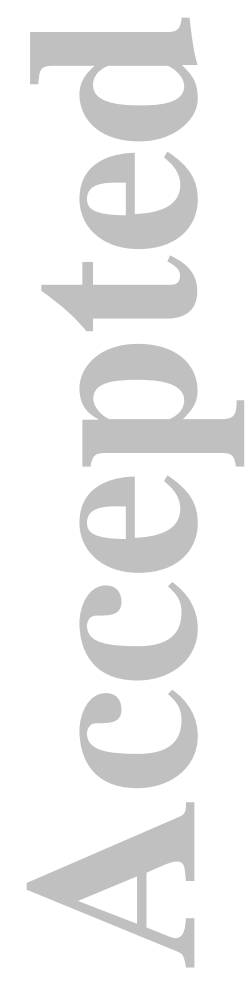


Table 5 - Satisfaction with Lifestyle Coach/MOVE! leaders in the ASPIRE-VA study

\begin{tabular}{|c|c|c|c|c|c|c|c|c|}
\hline$)$ & $\begin{array}{l}\text { Female } \\
\text { ASPIRE } \\
\text { - Phone }\end{array}$ & $\begin{array}{l}\text { Female } \\
\text { ASPIRE } \\
\text { - Group }\end{array}$ & $\begin{array}{l}\text { Female } \\
\text { MOVE }\end{array}$ & $\begin{array}{l}\mathrm{p} \text { - } \\
\text { value }\end{array}$ & $\begin{array}{l}\text { Male } \\
\text { ASPIRE } \\
\text { - Phone }\end{array}$ & $\begin{array}{l}\text { Male } \\
\text { ASPIRE } \\
\text { - Group }\end{array}$ & $\begin{array}{l}\text { Male } \\
\text { MOVE! }\end{array}$ & $\begin{array}{l}\mathrm{p}- \\
\text { value }\end{array}$ \\
\hline & $\mathrm{N}=19$ & $\mathrm{~N}=18$ & $\mathrm{~N}=14$ & & $\mathrm{~N}=100$ & $\mathrm{~N}=103$ & $\mathrm{~N}=105$ & \\
\hline $\begin{array}{l}\text { Did you have } \\
\text { confidence and } \\
\text { trust in the health } \\
\text { coach/MOVE! } \\
\text { leaders working } \\
\text { with you? }(\%)\end{array}$ & & & & 0.03 & & & & 0.03 \\
\hline Yes, always & 100 & 100 & 71 & & 94 & 93 & 89 & \\
\hline Yes, sometimes & 0 & 0 & 21 & & 6 & 6 & 4 & \\
\hline No & 0 & 0 & 7 & & 0 & 1 & 7 & \\
\hline $\begin{array}{l}\text { How would you } \\
\text { rate the courtesy } \\
\text { of your health } \\
\text { coach/the MOVE! } \\
\text { leaders? }(\%)\end{array}$ & & & & 0.26 & & & & 0.14 \\
\hline Excellent & 89 & 88 & 64 & & 86 & 86 & 70 & \\
\hline Very good & 11 & 12 & 29 & & 11 & 9 & 21 & \\
\hline Good & 0 & 0 & 7 & & 3 & 7 & 7 & \\
\hline Fair & 0 & 0 & 0 & & 0 & 1 & 1 & \\
\hline Poor & 0 & 0 & 0 & & 0 & 0 & 17 & \\
\hline $\begin{array}{l}\text { Did you feel like } \\
\text { you were treated } \\
\text { with respect and } \\
\text { dignity during } \\
\text { your lifestyle } \\
\text { coaching sessions } \\
\text { [the MOVE! } \\
\text { sessions, visits, or } \\
\text { phone calls]? (\%) }\end{array}$ & & & & 0.07 & & & & 0.41 \\
\hline Always & 100 & 100 & 86 & & 97 & 98 & 95 & \\
\hline Sometimes & 0 & 0 & 14 & & 2 & 2 & 5 & \\
\hline No & 0 & 0 & 0 & & 1 & 0 & 0 & \\
\hline $\begin{array}{l}\text { When you had } \\
\text { important } \\
\text { questions to ask } \\
\text { your health } \\
\text { coach/MOVE! } \\
\text { leaders, did you } \\
\text { get answers you } \\
\text { could } \\
\text { understand? (\%) }\end{array}$ & & & & 0.003 & & & & 0.05 \\
\hline Yes, always & 100 & 94 & 64 & & 95 & 89 & 90 & \\
\hline Yes, sometimes & 0 & 0 & 29 & & 5 & 8 & 4 & \\
\hline No & 0 & 0 & 0 & & 0 & 0 & 4 & \\
\hline
\end{tabular}


Figure 1 - Percent weight loss among women Veterans in each study arm from baseline to 12 months in the ASPIRE-VA study

$$
\text { (1) }
$$

Figure 2 - Percent weight loss among men Veterans in each study arm from baseline to 12 months in the ASPIRE-VA study

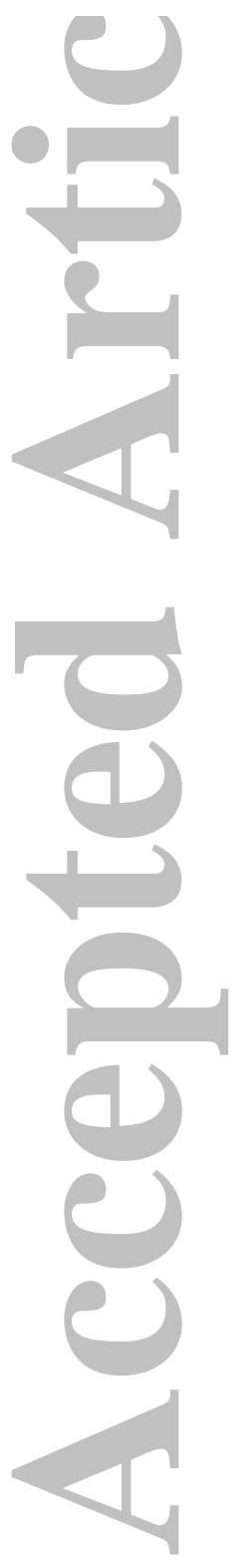


Figure 1 - Percent weight loss among women Veterans in each study arm from baseline to 12 months in the ASPIRE-VA study
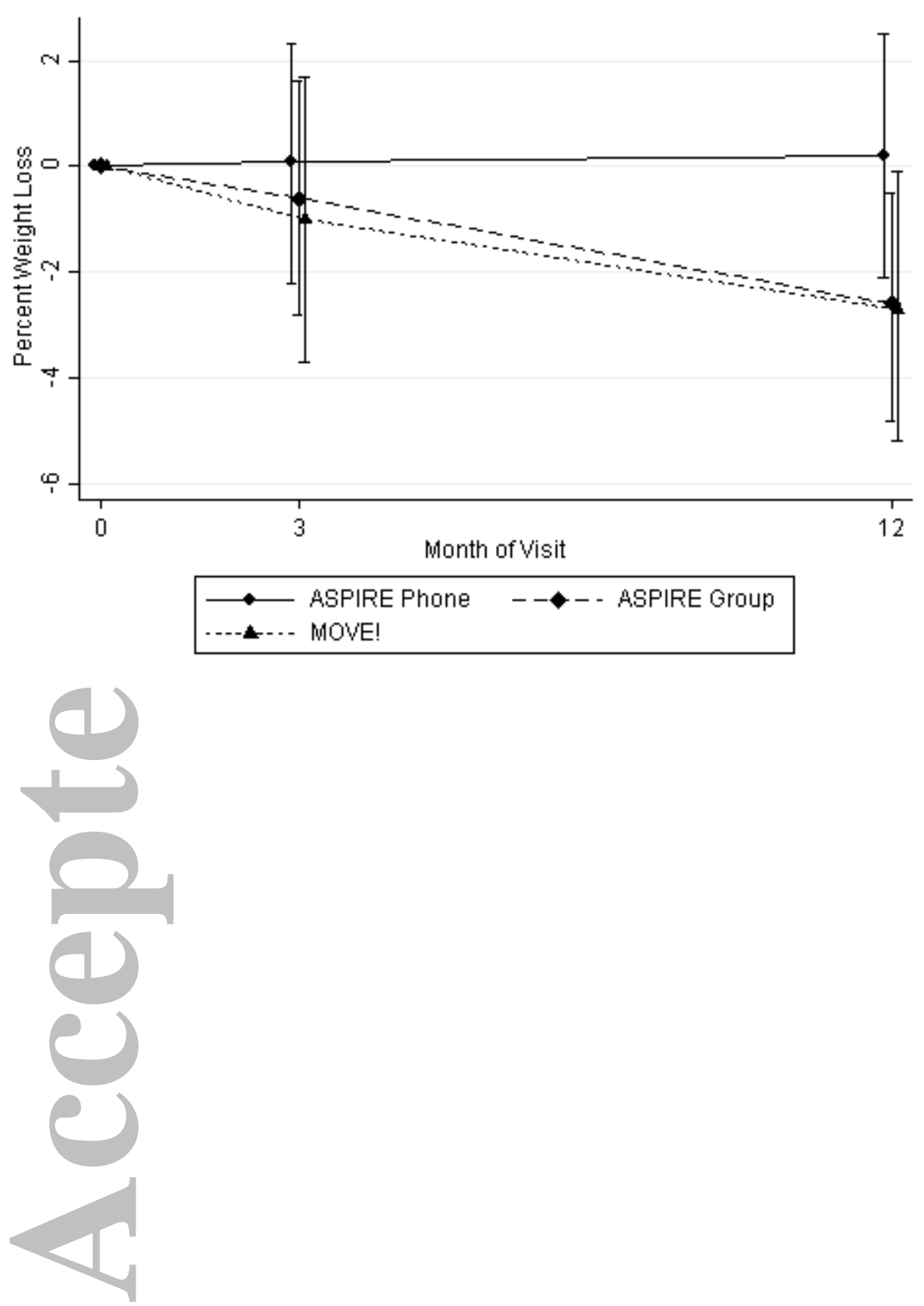
Figure 2 - Percent weight loss among men Veterans in each study arm from baseline to 12 months in the ASPIRE-VA study
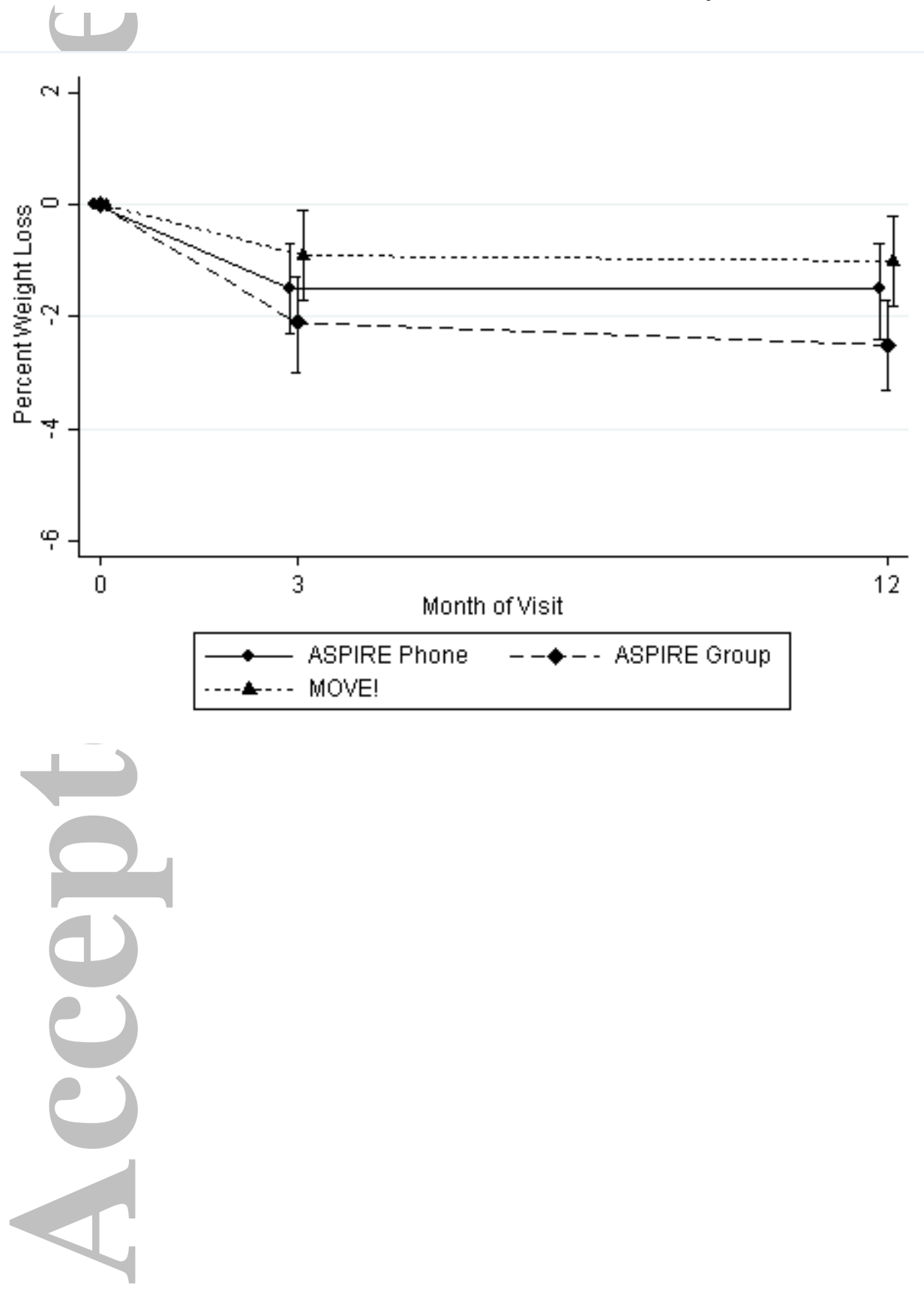


\section{Sex differences in weight loss in the ASPIRE-VA behavioral weight loss intervention trial}

Varsha Vimalananda, MD, MPH ${ }^{1,2}$;

Laura Damschroder, MS, MPH${ }^{3}$;

David Goodrich, EdD ${ }^{3}$;

Carol A. Janney, $\mathrm{PhD}^{3}$;

H. Myra Kim, $\mathrm{ScD}^{4}$;

Robert Holleman, $\mathrm{MPH}^{3}$;

Leah Gillon, $\mathrm{MSW}^{3}$;

Lesley Lutes, $\mathrm{PhD}^{5}$,*

${ }^{1}$ Center for Healthcare Organization and Implementation Research, Bedford VA Medical Center, Bedford MA USA; ${ }^{2}$ Boston University School of Medicine, Boston MA USA; ${ }^{3}$ VA Center for Clinical Management Research, VA Ann Arbor Healthcare System, Ann Arbor MI USA; ${ }^{4}$ Center for Statistical Consultation and Research, University of Michigan, Ann Arbor MI USA; ${ }^{5}$ Department of Psychology, East Carolina University, Greenville NC USA; * present address: Department of Psychology, University of British Columbia - Okanagan Campus, Kelowna, Canada

Keywords: sex, women, trial, weight loss, behavioral intervention, small changes

Running title: Sex differences in weight loss in ASPIRE-VA

Corresponding Author:

Varsha Vimalananda, MD, MPH

Center for Healthcare Organization and Implementation Research (152)

Bedford VA Medical Center

200 Springs Road

Bedford MA 02476

Email: Varsha.vimalananda@va.gov

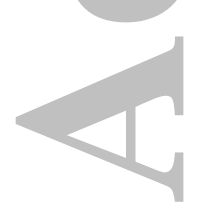


Table S1: Diet and exercise measures among women and men in each study arm at 3 and 12 months in the ASPIRE-VA study

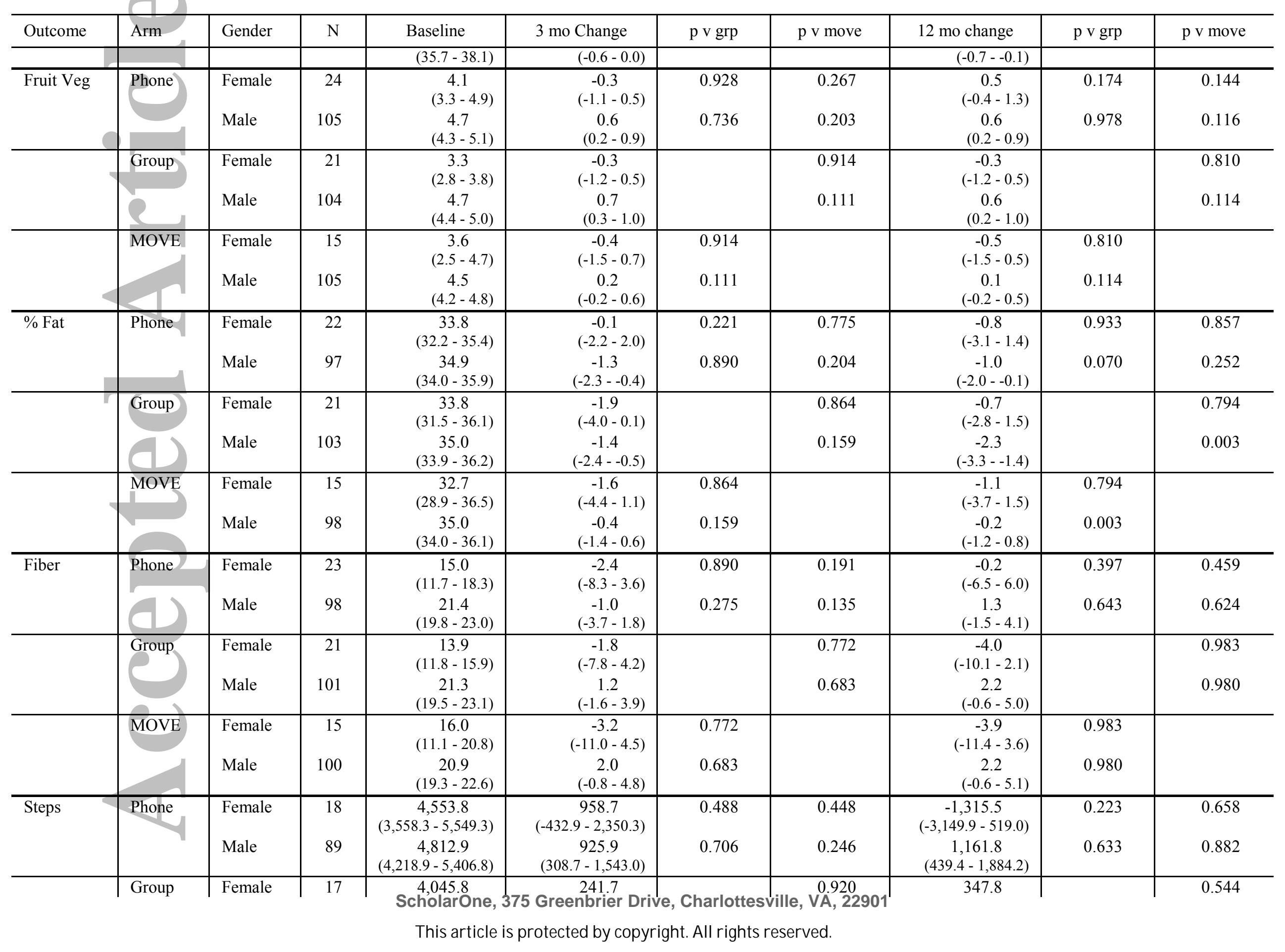




\begin{tabular}{|c|c|c|c|c|c|c|}
\hline & 5.1749 .80 & 435910.40 .5 & $\$ 97$ & $\begin{array}{l}(3,069.9-5,021.6) \\
(4,105.8-5,424.4)\end{array}$ & $\begin{array}{r}(-1,234.8-1,718.2) \\
(75.7-1,423.8)\end{array}$ & $\begin{array}{r}(-1,600.4-2,296.1) \\
(171.7-1,649.2)\end{array}$ \\
\hline $\begin{array}{l}\text { MOVE Fema } \\
\text { Male } 644,66\end{array}$ & $\begin{array}{l}\text { e } 114,339.0 \\
0.9343 .70 .4\end{array}$ & $\begin{array}{ll}122.2 & 0.920 \\
35 & 1,259.40\end{array}$ & $\begin{array}{l}-622.70 . \\
597\end{array}$ & $\begin{array}{l}44 \\
(2,550.7-6,127.3) \\
(4,072.8-5,249.0)\end{array}$ & $\begin{array}{r}(-1,687.2-1,931.7) \\
\quad(-420.6-1,108.0)\end{array}$ & $\begin{array}{r}(-3,082.4-1,836.9) \\
(199.6-2,319.3)\end{array}$ \\
\hline
\end{tabular}

